\title{
Do Socio-Economic Factors Play a Role in Delayed Presentation of Complicated Chronic Otitis Media (Squamous type)?
}

\author{
Nidhi Vohra Maggon, ${ }^{1}$ Ashwani Sethi, ${ }^{1}$ Harikesh, ${ }^{1}$ Surendra Vishwasrao Pimparkar ${ }^{1}$
}

\section{Introduction:}

\section{ABSTRACT}

The influence of Socioeconomic (SE) status on delayed reporting and consequent complications in cases of Chronic Otitis Media-squamous (COMS) has been investigated.

\section{Materials and Methods}

This prospective observational study included 34 patients with complicated COMS who presented to Otolaryngology Department at a tertiary care teaching hospital between December 2012 and December 2016. The patients were classified into 5 classes namely upper, upper middle, lower middle, upper lower, and lower based on a standardised real-time Kuppuswamy's SE status scale (KS) taking an average of consumer price indices for Industrial workers over 4 years (Jan '12 to Dec '16) as 267 and calculating their incomes. Level of education and occupation of the head of the family were the other components of KS which was calculated for each presenting patient.

\section{$\underline{\text { Results }}$}

Of the 34 patients, 15 were males (44\%) and 19 females (56\%) with their ages ranging from 18 months to 61 years (Mean-24.1 years, SD-17.3). 15 of the 34 patients (44.1\%) were in the Upper-lower SE class as per KS Scale, 13 were in lower-middle class (38.23\%), 5 were in Upper-middle class (14.70\%) and 1 patient belonged to Upper class (2.9\%). Though the literacy levels are integral to KS Scale a differential analysis showed 23 of the 34 patients/guardians had education level poorer or equal to Intermediate high school (67.64\%). The time gap between onset of symptoms of COMS and presentation with complications of COMS ranged from 9 months to 8 years with a mean time gap of 3.48 years (SD-2.01). There were 24extracranial complications and 21 intracranial complications with 10 patients having more than one complications. There was a strong inverse correlation between time gap and composite KS (-0.51). A differential analysis showed that Time gap most strongly correlated with education level of the head of the family (-0.615), followed by total family income (-0.403) and occupation of the head of the family (-0.329). Conclusion

There is a strong association between the SE status of the family and the occurrence of complications in COMS that is otherwise highly amenable to successful management. Level of education, nature of employment and family income that constitute KS scale have significant inverse correlation with delayed reporting and consequent complications of COMS. Level of Education is the greatest influence on the time gap.

Kevwords:

Otitis Media; Complications; Social Class; Literacy; Income

$\mathrm{T}$ The older terminology 'chronic suppurative otitis media' has been replaced by chronic otitis media (COM) as this condition may not always be associated with presence of a purulent discharge.

1 - Army College of Medical Sciences, Base Hospital, Delhi Cantonment, New Delhi 110010

\section{Corresponding author:}

Dr Nidhi Vohra Maggon

email: magnidhi@rediffmail.com
However, the differentiation between active COM and inactive COM needs to be appreciated becauseactive $\mathrm{COM}$ is associated with inflammation in the middle ear cleft with production of purulent discharge, while in a case of inactive COM it may not be so (though there is the potential for the ear to become active). ${ }^{1}$

Complications develop in a case of COM when the infection spreads from the middle ear to other important structures in its vicinity like the seventh nerve, inner ear, sigmoid sinus, duramater, meninges and intra 
cranial spaces. Traditionally the squamous disease has been considered to be the one more likely to cause complications, but a study by Singh and Maharaj reported that COM-mucosal also frequently results in complications. $^{2}$

Although the incidence of complications of COM has reduced significantly with the advent of effective antimicrobial treatment, they still remain a relatively common occurrence in developing countries. Lack of awareness, illiteracy, poor SE status, practise of using medication from non-qualified practitioners, use of home remedies and deficient health care facilities are important contributory factors towards this high incidence. $^{3}$

It has been observed by various workers that incidence of complications is significantly higher in patients from low SE status, due to disease negligence, poor access to medical facilities and delayed treatment. ${ }^{4}$ India has a standardised Kuppuswamy's scale (KS) to determine the socio-economic status of its population. ${ }^{5}$ We have carried out a prospective observational study on patients suffering from complications of COMS and their correlation, if any, with their SE status as measured objectively by KS. (Fig. 1)

\section{Materials and Methods}

34 patients who developed complications associated with COMS were treated in the Department of Otolaryngology between December 2012 and December 2016 and were included in this study. Extracranial complications of COMS studied were mastoiditis/ mastoid abscess, facial nerve palsy, labyrinthine fistula, petrositis and lateral sinus thrombosis. Intracranial complications of COMS were meningitis, brain abscess, sub-dural abscess and extra-dural abscess.

Patients who had undergone any ear surgery in the past, patients suffering from any pre-existing neurological co-morbidity or patients suffering from Diabetes Mellitus were excluded from this study.

All patients were evaluated by recording a detailed history (from guardians in case of children), a general physical examination, complete oto-laryngological examination, examination of the ear under microscope, an Oto-neurological assessment, microbial culture and antibiotic sensitivity, pure tone audiometry and radiological examination in form of Computerized tomography (CT) scan and/or magnetic resonance imaging .

All patients/guardians were thoroughly interviewed to ascertain their degree of literacy, levels of employment and cumulative family income to incorporate into Kuppuswamy's Socioeconomic Status Scale (Fig. 1). It is the most widely used scale for urban populations and was devised by Kuppuswamy in 1976. KS is a composite score of education and occupation of the head of the family along with monthly income of the family, which yields a score of 3-29. This scale classifies the study populations into high, middle, and low SE status5. The original 1976 version of KS scale has been updated several times primarily due to changes in income and inflation rate. Most significant upgrades were done by Mishra and Singh in $2003^{6}$ and later by Kumar et al in 2007.

The patients were classified into 5 classes namely upper, upper middle, lower middle, upper lower, and lower based on a standardised real-time Kuppuswamy's SE status scale (KS) taking an average of consumer price indices for Industrial workers over 4 years (Jan 12 to Dec 16) as 267 and calculating their incomes. Figure 1 shows the original KS which has undergone many modifications. The income levels were calculated on basis of a real-time link that calculates the current income on basis of the prevailing "Consumer Price Index".

All demographic parameters and the time gap between time of onset of symptoms of COMS and symptoms of complications were meticulously recorded.

All patients were given parenteral antibiotics covering gram positive, gram negative and anaerobic microorganisms and the antibiotics were modified (if required) depending on the result of culture and sensitivity reports. Supportive management in the form of analgesics, antipyretics, antiepileptics, steroids, osmotic diuretics and intravenous fluids were started as per the requirement of an individual case. All cases of intracranial or extracranial complications were managed appropriately with Neurosurgeon or Neurophysician 


\section{Education}

Profession or honors

Graduate or postgraduate

Intermediate or post-high school diploma

High school certificate

Middle school certificate

Primary school certificate

Illiterate

Occupation

Profession

Semiprofessional

Clerical, shopowner, farmer

Skilled worker

Semiskilled worker

Unskilled worker

Unemployed

Family income per month (in Rs. as per year 1976)

$\geq 2000$

1000-1999

750-999

500-749

300-499

101-299

$\leq 100$

Socioeconomic class

Upper class

Upper middle class

Lower middle class

Upper lower class

Fig. 1. Kuppuswamy’s Socioeconomic Status Scale (1976) 
Table I: Age-wise distribution of the patients

\begin{tabular}{|c|c|}
\hline AGE & NUMBER \\
\hline 0-10 Years & 03 \\
\hline 11-20 Years & 10 \\
\hline 21-30Years & 07 \\
\hline 31-40 Years & 08 \\
\hline 41-50 Years & 02 \\
\hline$>50$ Years & 04 \\
\hline
\end{tabular}

participation, wherever necessary. Age, gender, duration of symptoms, presenting signs and symptoms, laboratory and radiographic evaluations, treatment, operative findings, outcome, and hospital stay were recorded.

Time gap between the onset of the disease and the presentation due to symptoms of complications was recorded with great accuracy as were other parameters of KS of education, occupation and monthly income. KS collects data as ordinal data and also depicts it as a numerical quantity thus making the data highly amenable to statistical analysis.

\section{Results}

Of the 34 patients, 15 (44\%) were male and 19 (56\%) were female. The youngest patient was 18 months of age and the eldest 61 years. (Table I)

24 patients had a single complication and 10 had more than one complications. There were 21 intracranial complications and 24 extra cranial complications. (Table II)

The time gap/duration of ear symptoms of COMS i.e. otorrhea and hearing loss before the patient presented with symptoms of complications was on an average 03 years and 07 months (range- 09 months to 8 years). None of the patients were aware of the potential lifethreatening complications of an ear infection.
Table II: Observed complications in patients

\begin{tabular}{|c|c|}
\hline $\begin{array}{c}\text { COMPLICATION } \\
\text { mastoid abscess/ } \\
\text { mastoiditis }\end{array}$ & NUMBER OF PATIENTS \\
\hline Labyrinthine fistula & 02 \\
\hline Facial nerve palsy & 02 \\
\hline Petrous apicitis & 01 \\
\hline Meningitis & 08 \\
\hline $\begin{array}{c}\text { Brain abscess (Temporal / } \\
\text { cerebellar abscess) }\end{array}$ & $06(4 / 2)$ \\
\hline Subdural abscess & 02 \\
\hline Extra dural abscess & 05 \\
\hline \begin{tabular}{c} 
Lateral sinus thrombosis \\
\hline
\end{tabular} & 01 \\
\hline
\end{tabular}

3 patients were seropositive for HIV and none of them had any knowledge of their underlying condition and its influence on their otorrhea and hearing loss. The clinical presentations varied with the type of existing complications.

Of the 34 patients, 15 patients $(44.1 \%)$ belonged to a family of Upper-lower strata of KS scale, 13 patients $(38.23 \%)$ to Lower-middle strata, 5 patients $(14.70 \%)$ to Upper-middle strata and only 1 patient (2.9\%) belonged to Upper strata (Table III).

Only 08 of the 34 patients had consulted a qualified medical practitioner (MBBS and above)for their symptoms ,21 patients were being treated by unqualified local practitioners and remaining 5 patients presented for the first time ever with symptoms of complications to us. 21 of the total of 34 patients $(61.76 \%)$ were also found to be practising home remedies in the form of instillation of oil in the ear.

Surgical management was done in all cases in form of modified radical mastoidectomy. In cases of intracranial complications, the initial management was done by 
Table III: Numbers of patients in various classes as per KS scale

\begin{tabular}{|c|c|c|c|}
\hline STRATA & NO. OF PATIENTS (N=34) & PERCENTAGE & $\begin{array}{c}\text { AVERAGE TIME GAP } \\
\text { (YEARS) }\end{array}$ \\
\hline Upper-lower & 15 & $44.11 \%$ & 4.3 \\
\hline Lower-middle & 14 & $41.17 \%$ & 3.13 \\
\hline Upper-middle & 5 & $14.7 \%$ & 2.3 \\
\hline Upper & 1 & $2.9 \%$ & 1.75 \\
\hline
\end{tabular}

neurophysician/neurosurgeon followed by definitive management for ear pathology (after the patient was stable).

The average time gap in various SE strata was Upperlower-4.3 years, Lower-middle -3.13 years, Uppermiddle- 2.3 years and Upper-1.75 years (Table III).

There was an inverse correlation (Correlation coefficient -0.51) between time gap and KS scale. The higher the KS scale, higher was the strata the family belonged to and less was the average time gap.

We also correlated time gap with various constituents of the KS scale. The correlation between time gap \& education level of the head of the family was -0.615 , between time gap \& occupation of the head of the family was -0.329 and between time gap \& family income was -0.403 (Table IV).

\section{Discussion}

COMS is a disease of insidious onset and is often persistent in its course. It clinically manifests with aural discharge and hearing loss. Untreated, it frequently leads to severe, irreparable destruction and serious consequences. $^{8}$

COMS is a serious healthcare concern worldwide, not only because of the distress it causes to the patients and their families but also because of the substantial economic burden, financial losses in productivity and reduced quality of life of the affected individuals. ${ }^{9}$

This is one of the most common community health disorders of childhood in many developing countries including India. ${ }^{10}$ The availability of effective antimicrobial therapy by antibiotics has dramatically reduced the incidence of complications from acute otitis media (AOM) and COM. Antibiotics have largely replaced the earlier surgical intervention approach for treatment of complicated COM. ${ }^{11,12}$ Nevertheless,

Table IV: Correlation coefficients between time gap and KS scale \& components

\begin{tabular}{|c|c|c|}
\hline ENTITY 1 & ENTITY 2 & $\begin{array}{c}\text { CORRELATION } \\
\text { COEFFICIENT }\end{array}$ \\
\hline Time Gap & Composite KS & -0.51 \\
\hline Time Gap & Education level & -0.615 \\
\hline Time Gap & Occupation of head & -0.329 \\
\hline Time Gap & Family income & $\mathbf{- 0 . 4 0 3}$ \\
\hline
\end{tabular}


complications remain quite frequent, have high morbidity and mortality rates, and pose a challenge to the otorhinolaryngologist. ${ }^{13,14,15}$

The prevalence of COM in Southeast Asia, Africa, and Western Pacific countries is estimated to be $2-4 \%$, and that in North America and European countries is $<$ $2 \% .{ }^{16}$ Many studies from various countries have reported a significant decline in the prevalence of COMS on an annual basis due to wide use of antibiotics, improved nutrition and hygiene status secondary to economic growth, improved public welfare and easy access to medical facilities. ${ }^{13}$ COMS is virtually non-existent in the developed world but still constitutes a major public health problem in Africa, Asia and Latin America and Nigeria. ${ }^{17}$ Wakode and Joshi in a landmark study of 4104 school students in Yavatmal district of Western India found an overall $3 \%$ prevalence of COM and found a statistically significant association between SE status, as determined by a India-specific standardised KS scale, and occurrence of COM. ${ }^{18}$

We decided to conduct a prospective study on patients who presented to us with symptoms of a complicated COMS and tried to find a correlation with the SE status of the families that they belonged to. India has a standardised Kuppuswamy scale for SE status that varies each year based on Consumer Price Index (CPI) for the year and since the study was conducted over 4 years, the average CPI for Industrial workers was taken as 267 and calculation of KS done.

We observed that there was no significant gender difference between the patients (15 males, 19 females). 14 of the 34 patients $(41.17 \%)$ were less than 18 years of age. 10 of these 14 patients $(29.41 \%)$ were less than 8 years of age. In a study by Qureshi et al the incidence of complicated COMS in children under 5 years was $31.1 \%$ which is very close to our observations. ${ }^{4} 20$ of the 34 patients were in the adult age group (20 to 61 years).

The time gap from onset of symptoms of COMS i.e. otorrhea and/or hearing loss, to presenting symptoms of complications ranged widely from 9 months to 8 years with a mean of 3.48 (approximately 3 years and 6 months).Interestingly the mean time gap between onset and complications was on an average only 1.5 years in paediatric age group thus indicating a significant early reporting in children. Qureshi et al found this mean time gap to be only 1.69 years in their study of 65 patients. ${ }^{4}$ Our study reveals a significantly greater delay in reporting ( 3.48 years).

15 of the 34 patients $(44.11 \%)$ belonged to Upperlower strata of composite KS scale.

A further analysis of these 15 patients revealed that 11 of these patients/guardians were employed in unskilled jobs and none of these had education beyond Intermediate. 3 of them were in a semi-skilled employment and 1 of them ran a retail shop. 14 of these families earned less than Rs. 10294 per month and the only exception (Shopkeeper) earned over Rs. 15000.

14 of the 34 patients $(41.17 \%)$ belonged to Lowermiddle strata of the KS scale. 10 of these 14 patients were in a semi-skilled employment, 2 in skilled employment and one of them had a clerical job. 8 of these 14 patients had family income between Rs. 1029515441, 4 families earned less than Rs. 10294 and one family earned around Rs. 17000 per month. Education levels in this group also were rather modest though 4 of the 14 patients were graduates.

Five of the 34 families (14.7\%) belonged to the Uppermiddle strata of KS scale. All of them were graduates and 3 of them were in clerical or semi-professional employment and 2 were in skilled employment.

Only one patient came from Upper strata of KS scale who was an employed professional and his income exceeded Rs.20590 per month.

An extensive search of available literature did not show us an Indian study that objectively determined the correlation between occurrence of complicated COMSand a standardised composite SE status scale such as KS scale. In order to further refine the inferential scope of the collected data, we determined the correlation coefficient between time gap and 3 components of KS scale viz. education level of the head of the family, occupation of the head of the family and the total family income. Understandably, there was an inverse correlation $(-0.51)$ between time gap and KS scale. The higher the KS scale, higher was the strata the family belonged to and less was the time gap. Further analysis revealed that there was a stronger inverse correlation between educational level of the head of 
the family and the time gap $(-0.615)$. The correlation coefficient between time gap and occupation of the head of the family was again inverse at -0.329 , though much weaker than with education status. The correlation coefficient between time gap and family income was -0.403 (Table IV). Therefore, as per this study within the KS scale it was the education level that most strongly correlated inversely with delayed presentation of patients of complicated COMS.

\section{Conclusion}

COMS is a common disease of the developing world with malnutrition, over-crowding, substandard hygiene, frequent upper respiratory tract infections and underresourced health care listed as risk factors. ${ }^{13,16,17,19}$ The poorer rural communities have the highest prevalence. ${ }^{15,18}$ Patients in the developing world report very late and tolerate its discomfort with potentially fatal consequences not only because of insufficient work force and health care facilities but also due to unawareness and cost or accessibility of health care. . $^{18,20,21}$ We have tried to evaluate the impact of socioeconomic status on the neglect of early symptoms of COMS, a delay in reporting and the consequent complications that are potentially fatal, in an objective manner. We have observed that SE status indeed correlates inversely with delay in reporting but within that parameter the level of education is the foremost influence on the delay.

\section{References}

1. G.G. Browning, S.N. Merchant, G. Kelly, I.R. Swan, R. Canter, S.W. McKerrow, M. Gleeson, G.G. Browning, M.J. Bruton (Eds.), et al., Chronic Otitis Media. Scott-Brown's Otorhinolaryngology Head and Neck (7th ed.), vol. 19 (237c), Edward Arnold (Publisher) Ltd. (2008), p. 3410

2. Singh B, Maharaj TJ. Radical mastoidectomy-Its place in otitic intracranial complications. J Laryngol Otol. 1993; 107(12):1113-8. doi: 10.1017/S0022215100125435

3. Rupa V, Jacob A, Joseph A. CSOM: Prevalence and practices among rural south indian children. Int $\mathrm{J}$ Pediatr Otorhinolaryngol, 1999; 48 (3):217-21

4. Qureshi SR, Rehman UR. Demographic influences on complicated chronic suppurative otitis media. Indian J Otol [serial online] 2015 [cited 2017 May 25]; 21:170-3

5. Kuppuswamy B. Manual of Socioeconomic Status (Urban) 1st ed. Delhi: Manasayan; 1981. pp. 66-72

6. Mishra D, Singh HP. Kuppuswamy's socioeconomic status scale - A revision. Indian J Pediatr. 2003;70:273-4

7. Kumar N, Shekhar C, Kumar P, Kundu AS. Kuppuswamy's socioeconomic status scale - Updating for 2007. Indian J Pediatr. 2007;74:1131-2

8. Shenoi PM. Management of chronic suppurative otitis media. In: Booth JB Editor. Scott Brown's Otolaryngology. 5. London: Butterworths; 1987 pp. 215-37

9. Rehab Alwotayan, Khaled Alabdulhadi. Otitis media: A review for the family physician. Bull Kuwait Inst Med specializat, 2003; 2:83-9

10. Berman S. Otitis media in developing countries. Paediatrics. 1996; 96:126-31

11. Wanna G B, Dharamsi L M, Moss J R, Bennett M L, Thompson R C, Haynes D S. Contemporary management of intracranial complications of otitis media. Otol Neurotol. 2010; 31(1):111-7

12. Carvalhal L HSK, Costa S S, Cruz O LM. Complicações das otites médias Porto Alegre: Artmed; 2006, pp. 334-41

13. Lin Y S, Lin L C, Lee F P, Lee K J. The prevalence of chronic otitis media and its complication rates in teenagers and adult patients. Otolaryngol Head Neck Surg. 2009; 140(2):165-70

14. Dubey S P, Larawin V. Complications of chronic suppurative otitis media and their management. Laryngoscope 2007; 117(2):264-7

15. Neves B MJ, Weckx L LM. Paralisia do nervo abducente como complicação de otite media aguda [Abducens nerve palsy as a complication of acute otite media] Braz J Otorhinolaryngol. $2002 ; 68: 280-3$

16. Lasisi AO, Olaniyan FA, Muibi SA, Azeez IA, Abdulwasiu $\mathrm{KG}$, Lasisi TJ, et al. Clinical and demographic risk factors associated with chronic suppurative otitis media. Int J Pediatr Otorhinolaryngol. 2007; 71:1549-54. pmid:17643499

17. J.M. Acuin. Chronic suppurative otitis media: A disease waiting for solutions. Comm Ear Hearing 2007; 4(6):17-9

18. Wakode PT, Joshi SV, Gawarle SH. Chronic suppurative otitis media in school going children. Indian Journal of Otolaryngology and Head and Neck Surgery. 2006; 58(2):1525.

19. Ologe FE, Nwawolo CC. Chronic suppurative otitis media in school pupils in Nigeria. East Afr Med J. 2003; 80:130-4

20. Dhingra PL, Dhingra S. Diseases of Ear, Nose and Throat and head and Neck Surgery, 6 th ed. Elseiver Health Sciences 2014

21. Okafor BC. The chronic discharging ear in Nigeria. J Laryngol Otol. 1984; 98:113-9. 